\title{
O CASO SÉTIMO GARIBALDI E AS CONTRADIÇÕES DO SISTEMA DE JUSTIÇA FRENTE A DECISÕES DO SISTEMA INTERAMERICANO DE DIREITOS HUMANOS.
}

\section{EL CASO SÉTIMO GARIBALDI Y LAS CONTRADICCIONES DEL SISTEMA DE JUSTICIA EN RELACIÓN CON LAS DECISIONES DEL SISTEMA INTERAMERICANO DE DERECHOS HUMANOS.}

${ }^{1}$ Luciana Silva Garcia

\section{RESUMO}

O artigo procurará apontar as posturas do Estado brasileiro perante o Sistema Interamericano de Direitos Humanos (SIDH), com ênfase no Sistema de Justiça, com uma breve análise das reformas do Sistema de Justiça empreendidas a partir da promulgação da Constituição Federal de 1988, para verificar se e como o tema do tratamento de graves violações de Direitos Humanos foi recepcionado pelas reformas e, por fim, o trâmite do caso Sétimo Garibaldi versus Brasil no SIDH e as posições do Poder Judiciário brasileiro frente à sentença da Corte Interamericana de Direitos Humanos.

Palavras-chave: Violações de direitos humanos, Sistema interamericano de direitos humanos, Sistema de justiça, Reformas

\section{RESUMEN}

El artículo identifica las posiciones del Estado de Brasil antes el Sistema Interamericano de Derechos Humanos, con énfasis en el Sistema de Justicia (SIDH), con un breve análisis acerca de las reformas del Sistema de Justicia llevadas a cabo desde la promulgación de la Constitución Federal de 1988, para ver si y cómo el tema de violaciónes graves de los Derechos Humanos fue bien recibido por las reformas y, por último, el proceso del caso Séptimo Garibaldi contra Brasil en el SIDH y las posiciones de los tribunales brasileños acerca de la sentencia de la Corte Interamericana de Derechos Humanos.

Palabras-claves: Violaciones de derechos humanos, Sistema interamericano de derechos humanos, Sistema de justicia, Reformas

\footnotetext{
${ }^{1}$ Doutoranda pela Universidade de Brasília - UnB, Distrito Federal (Brasil). Professora de Direito pela Universidade de Brasília - UnB, Distrito Federal (Brasil). E-mail: luciana.silvagarcia@gmail.com
} 


\section{INTRODUÇÃO - OBJETIVOS DO ARTIGO}

O presente artigo é fruto de reflexões (ainda preliminares) que estão sendo realizadas no âmbito de projeto de pesquisa de doutorado em Direito em curso. O projeto tem como objetivo geral compreender como se dá a relação entre o Sistema de Justiça e o Poder Executivo frente aos casos do Programa de Proteção a Defensores de Direitos Humanos (PPDDH) e do Sistema Interamericano de Direitos Humanos (SIDH), identificando instrumentos, mecanismos e processos que contribuam para uma reforma das instituições, com vistas ao estabelecimento de uma relação dialógica entre os poderes, para tratamento de graves violações de Direitos Humanos, mediante o estudo de dois casos específicos, sendo um deles o caso Sétimo Garibaldi versus Brasil.

Os estudos realizados até então, demonstram contradições do Sistema de Justiça $^{1}$ brasileiro no tratamento de grave violação de Direitos Humanos, mesmo já tendo sido constatada enquanto tal por um sistema internacional de proteção aos Direitos Humanos, legitimado pelo Brasil para apontar violações e indicar reparações, de que vítimas sofreram por ações ou omissões do Estado. Decisões e posições contrastantes são comuns e inerentes ao Sistema de Justiça, tendo em vista seus órgãos não serem blocos monolíticos: promotores e juízes são dotados de independência funcional conforme previsão da Constituição Federal. A questão que se coloca é como o Sistema de Justiça lida com graves violações de Direitos Humanos quando já foram identificadas e reconhecidas enquanto tal pelo próprio Estado brasileiro, mas por outras estruturas e funções.

O artigo, então, procurará apontar as posturas do Estado brasileiro perante o Sistema Interamericano de Direitos Humanos, com ênfase no Sistema de Justiça; fará uma breve análise das reformas do Sistema de Justiça empreendidas a partir da promulgação da Constituição Federal de 1988, para verificar se e como o tema do tratamento de graves violações de Direitos Humanos foi recepcionado pelas reformas e, por fim, o trâmite do caso Sétimo Garibaldi versus Brasil no SIDH e as posições do Poder Judiciário brasileiro frente à sentença da Corte Interamericana de Direitos Humanos (Corte IDH ou Corte).

\footnotetext{
${ }^{1}$ Segundo Sadek (2010), o Sistema de Justiça é mais amplo que o Poder Judiciário e envolve diversos atores, como o advogado (pago ou dativo), o delegado de polícia, o promotor público, o juiz e possui uma organização espacial, que define as comarcas (as menores unidades judiciais), uma organização processual, que define o tipo de vara, de acordo com o ramo do Direito que trata (criminal, cível, etc.), além de uma organização recursal, que trata dos tribunais, sendo que a esta organização judicial é acompanhada pelas organizações do Ministério Público e parcialmente pelas Delegacias de Polícia.
} 


\section{POSTURAS DO ESTADO BRASILEIRO PERANTE O SIDH}

A Corte IDH e a Comissão Interamericana de Direitos Humanos (CIDH) são órgãos que compõem o SIDH, responsáveis por garantir o cumprimento da Convenção Americana de Direitos Humanos (CADH) e demais convenções pelos Estados-partes. ${ }^{2}$ Em relação ao Brasil, tramitam perante a Comissão Interamericana cento e vinte e cinco casos em diferentes fases, sendo vinte e sete em Admissibilidade, cinquenta e seis em Análise de Mérito, quatorze em Solução Amistosa, dezoito em Cumprimento de Recomendações e dez em Medidas Cautelares. Já na Corte IDH tramitam três casos em fase de cumprimento de sentença, três em fase de medidas provisórias e dois casos em fase de instrução, tendo o Brasil sido condenado pela Corte em quatro casos e absolvido em um caso. ${ }^{3}$

Segundo Abramovich (2009), atualmente, os órgãos que compõem o SIDH procuram não apenas reparar as vítimas nos casos particulares, tendo por base as violações à Convenção Americana de Direitos Humanos, mas também fixam um conjunto de princípios e parâmetros, com o propósito de incidir na qualidade dos processos democráticos e no fortalecimento dos principais mecanismos domésticos de proteção dos direitos. O desafio atual do SIDH é melhorar as condições estruturais que garantem a efetividade dos direitos no âmbito interno, com ênfase nos temas relativos ao funcionamento dos sistemas de administração da justiça que têm impacto ou relação com o exercício dos direitos humanos; à preservação da esfera pública democrática nos países da região, às novas demandas de igualdade de grupos e coletividades que se projetam sobre muitos dos assuntos institucionais do Estado; à incidência na jurisprudência dos tribunais nacionais que aplicam as normas de direito internacional dos direitos humanos e em estabelecer orientação geral de algumas políticas públicas no âmbito interno.

\footnotetext{
${ }^{2}$ A função principal da CIDH é a de promover a observância e a defesa dos Direitos Humanos e servir como órgão consultivo da Organização dos Estados Americanos nesta matéria. A Comissão, por um lado, tem competências com dimensões políticas, entre as quais a realização de visitas in loco e a preparação de relatórios sobre a situação dos Direitos Humanos nos Estados membros. Realiza também funções com uma dimensão quase judicial: recebe as denúncias de particulares ou organizações relativas a violações de Direitos Humanos, examina essas petições e adjudica os casos no suposto de que se cumpram os requisitos de admissibilidade. A CorteIDH é um dos três tribunais regionais de proteção dos Direitos Humanos, conjuntamente com a Corte Europeia de Direitos Humanos e a Corte Africana de Direitos Humanos e dos Povos. É uma instituição judicial autônoma cujo objetivo é aplicar e interpretar a Convenção Americana. A Corte Interamericana exerce uma função contenciosa, dentro da qual se encontra a resolução de casos contenciosos e o mecanismo de supervisão de sentenças; uma função consultiva; e a função de ditar medidas provisórias.

3 Todas as informações estão disponíveis nas páginas eletrônicas da CIDH e da Corte IDH: http://www.oas.org/es/cidh/ e http://www.corteidh.or.cr/index.php/es. Acesso em Acesso em 15 de jun.2105.
} 
A atuação do Brasil junto ao $\mathrm{SIDH}^{4}$ também se alterou com o passar dos anos, a contar da ratificação da CADH em 1992 e o reconhecimento da jurisdição da Corte IDH em 1998. Desde as primeiras recomendações da CIDH em 1997 (relativas ao caso Newton Coutinho Mendes e outros) $)^{5}$ e a primeira sentença contra o Estado brasileiro pela CorteIDH em 2006 (sobre o caso Ximenes Lopes), o Brasil, segundo Ventura e Cedra (2013) teve uma atuação inicialmente indiferente e algumas vezes formal no atendimento às recomendações e decisões do SIDH. Exemplificam-se, neste cenário, as posições do Sistema de Justiça, em relação a dois casos: Maria da Penha Maia Fernandes versus Brasil (caso 12.051, de 2001) ${ }^{6}$ no âmbito da CIDH e o caso Gomes Lund e outros versus Brasil, conhecido como caso da Guerrilha do Araguaia (sentença de 24 de novembro de 2010) no âmbito da CorteIDH.

Sobre o caso Maria da Penha, a CIDH recomendou expressamente ao Estado brasileiro que completasse de forma rápida e efetiva o processamento penal do responsável da agressão e tentativa de homicídio em prejuízo da vítima e ainda que realizasse uma investigação séria, imparcial e exaustiva a fim de determinar a responsabilidade pelas irregularidades e atrasos injustificados que impediram o processamento rápido e efetivo do responsável, bem como tomar as medidas administrativas, legislativas e judiciárias correspondentes sobre as violências sofridas pela vítima (CIDH, 2001).

A despeito dos avanços trazidos pela Lei n. ${ }^{\circ} 11.340 / 2006$ (Lei Maria da Penha), cuja criação também foi impulsionada pelas recomendações da CIDH ao Estado Brasileiro e por intensa atuação da vítima e do movimento feminista e de organizações de direitos das mulheres junto ao Poder Executivo e Poder Legislativo ${ }^{7}$, o efetivo processamento penal do responsável pela agressão e tentativa de homicídio demorou 17 (dezessete) anos para se consumar, desconsiderando completamente as recomendações da Comissão sobre o

\footnotetext{
${ }^{4}$ De acordo com Peres (2014), há um fluxo de coordenação das respostas ao SIDH entre a Advocacia-Geral da União (AGU), o Ministério das Relações Exteriores (MRE) e a Secretaria Especial de Direitos Humanos (SEDH) do Ministério das Mulheres, da Igualdade Racial e dos Direitos Humanos. O MRE recebe as demandas e decide a redação final dos relatórios do Estado brasileiro. A defesa jurídica do Estado brasileiro nos casos de admissibilidade perante a CIDH é de atribuição da AGU. Todas as outras fases na CIDH e perante a Corte IDH são de atribuição da SEDH.

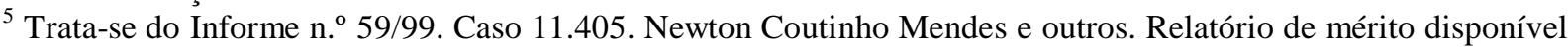
em: http://www.cidh.oas.org/annualrep/98span/Fondo/Brasil\%2011.405.htm. Acesso em: 15 de jun. 2015.

${ }^{6}$ Relatório n. ${ }^{\circ}$ 54/01. Caso 12.051. Maria da Penha Maia Fernandes, de 4 de abril de 2001. Relatório de mérito disponível em: https://www.cidh.oas.org/annualrep/2000port/12051.htm. Acesso em 15 de jun.2105.

${ }^{7}$ Sobre a articulação entre o governo e os movimentos feministas e de mulheres para a formulação e aprovação da lei e a tradução da pauta de lutas desses movimentos pelo Estado, ver Macdowell (2010). Sobre dinâmicas transnacionais com implicações para a inclusão de política de grupos vulneráveis, a partir do caso Maria da Penha Maia Fernandes diante da CIDH e o processo de elaboração e promulgação da Lei Maria da Penha, ver Bernardes (2014).
} 
assunto, o que indica a inércia do Sistema de Justiça em efetivar as garantias judiciais e a proteção judicial, assegurados pelos artigos $8^{\circ}$ e 25 da Convenção Americana.

Quanto ao caso Gomes Lund versus Brasil, em novembro de 2010, a CorteIDH determinou ao Estado a condução eficaz, perante a jurisdição ordinária, da investigação penal dos fatos relativos ao caso, a fim de esclarecê-los, determinar as correspondentes responsabilidades penais e aplicar efetivamente as sanções e consequências que a lei preveja (CorteIDH, 2010). A Corte ainda afirmou que as disposições da Lei de Anistia (Lei n. 6.683/1979) que impedem a investigação e sanção de graves violações de direitos humanos são incompatíveis com a Convenção Americana, carecem de efeitos jurídicos e não podem representar um obstáculo para a investigação dos fatos relativos ao caso, nem para a identificação e punição dos responsáveis, e tampouco podem ter igual ou semelhante impacto sobre outros casos de graves violações de direitos humanos consagrados na Convenção Americana ocorridos no Brasil (CorteIDH, 2010).

Entretanto, em abril de 2010, o Supremo Tribunal Federal (STF) decidiu, no âmbito da Arguição de Descumprimento de Preceito Fundamental (ADPF) n. ${ }^{\circ}$ 153, a aplicabilidade da Lei de Anistia, declarando válida a interpretação de que haveria uma anistia bilateral na lei de 1979, que se trataria de um acordo político fundante da Constituição Democrática de 1988 e que somente o Poder Legislativo brasileiro poderia revê-lo (Garcia, 2012). Assim, um impasse instalou-se sobre o caso e as posições do Judiciário brasileiro têm desconsiderado a sentença da Corte e mantido a aplicabilidade da Lei de Anistia de $1979 .^{8}$

Contraditoriamente a este cenário, o Conselho Nacional de Justiça (CNJ) tem feito aproximações importantes com os órgãos do SIDH: em 2015, firmou acordo de

\footnotetext{
${ }^{8}$ A Corte IDH, em resolução sobre supervisão do cumprimento da sentença, de 17 de outubro de 2014, observou com preocupação que por mais de três anos da emissão da sentença somente tinha se iniciado duas ações penas que compreendem dois supostos responsáveis pelas violações cometidas contras as vítimas. E decisões judiciais internas posteriores à sentença que aplicaram a Lei de Anistia indicam um desconhecimento dos alcances do decidido pela Corte e os parâmetros interamericanos em matéria de investigação, julgamento e punição dos responsáveis por graves violações aos direitos humanos. A Corte ainda recordou que, ao pronunciar-se sobre a incompatibilidade das disposições da Lei de Anistia brasileira com a Convenção Americana, também observou que não foi exercido um controle de convencionalidade pelas autoridades judiciais do Estado, e que pelo contrário, a referida decisão do Supremo Tribunal Federal confirmou a validez da interpretação da Lei de Anistia sem considerar as obrigações internacionais do Brasil derivadas do direito internacional. A Corte ainda considerou que no marco das ações penais iniciadas por fatos do caso Gomes Lund e outros foram proferidas decisões judiciais que interpretam e aplicam a Lei de Anistia do Brasil de uma forma que continua comprometendo a responsabilidade internacional do Estado e perpetua a impunidade de graves violações de direitos humanos em claro desconhecimento do decidido por esta Corte e pelo Direito Internacional dos Direitos Humanos. A Corte manifestou-se expressamente pela existência da obrigação dos juízes e tribunais internos de realizar um controle de convencionalidade, especialmente quando existe coisa julgada internacional, pois juízes e tribunais têm um importante papel no cumprimento ou implementação da Sentença da Corte Interamericana. (CorteIDH, 2014)
} 
cooperação com a $\mathrm{CIDH}^{9}$, que tem por objetivo promover a educação e a difusão dos direitos humanos na cultura jurídica brasileira para melhor distribuição de Justiça segundo os padrões do Sistema Interamericano de Proteção aos Direitos Humanos da OEA e no $156^{\circ}$ período de sessões da Comissão, o presidente do CNJ e do STF, Ricardo Lewandowski, apresentou o projeto Audiências de Custódia ${ }^{10}$, em uma audiência temática solicitada à CIDH pelo próprio conselho. ${ }^{11}$ Foi a primeira vez que o chefe máximo de um dos Poderes da República participou de audiência de órgão integrante do Sistema Interamericano de Proteção aos Direitos Humanos.

A atuação diversa e muitas vezes contraditória do Estado brasileiro, em especial do Sistema de Justiça, perante o SIDH, não corresponde à crescente importância que o ativismo jurídico transnacional ${ }^{12}$ e a utilização do litígio estratégico ${ }^{13}$ passaram a ter na atuação dos movimentos sociais e organizações da sociedade civil quanto à proteção dos Direitos Humanos. Vide o crescimento do número de petições enviadas à CIDH com denúncias à Convenção Americana nos últimos cinco anos: noventa e duas petições enviadas em 2014, oitenta e oito em 2013, noventa e seis em 2012, sessenta e oito em 2011 e setenta e seis em 2010. ${ }^{14}$ E mais, quase a totalidade dos casos em trâmite no SIDH denuncia o Estado brasileiro por violação aos artigos $8^{\circ}$ e 25 da Convenção Americana - direito às garantias judiciais e à proteção judicial. ${ }^{15} \mathrm{O}$ acesso à justiça é recorrentemente pautado por movimentos sociais e organizações de Direitos Humanos, o que indica a necessidade do diálogo entre o Poder Executivo e o Sistema de Justiça para garantir o cumprimento das recomendações e decisões do SIDH sobre o tema e a reforma daquelas instituições para proteger e garantir os Direitos Humanos.

\footnotetext{
${ }^{9}$ A íntegra do acordo de cooperação está disponível em: http://www.oas.org/es/cidh/mandato/docs/2015-acuerdobrasil.pdf. Acessado em 30 de out. 2015.

10 Sobre o Projeto Audiências de Custodia, ver página eletrônica do CNJ: http://www.cnj.jus.br/sistemacarcerario-e-execucao-penal/audiencia-de-custodia. Acessado em 30 de out. 2015.

11 A íntegra da audiência temática pode ser assistida pela página eletrônica da CIDH: http://www.oas.org/es/cidh/multimedia/sesiones/156/default.asp. Acesso em 30 de out. 2015.

${ }_{12}$ Como ensina Macdowell (2007, p. 28), o ativismo jurídico transnacional pode ser visto como uma tentativa não simplesmente de remediar abusos individuais, mas também de (re)politizar ou (re)legalizar a política de direitos humanos ao provocar as cortes internacionais ou sistemas quase judiciais de direitos humanos e levá-los a agirem diante das arenas jurídicas e políticas nacionais e locais.

${ }^{13} \mathrm{O}$ litígio estratégico busca, por meio do uso do judiciário e de casos paradigmáticos alcançar mudanças sociais, sendo escolhidos como ferramentas para a transformação da jurisprudência e formação de precedentes, que possam provocar mudanças legislativas ou de políticas públicas. Sobre litígio estratégico e a atuação dos movimentos sociais e organizações de direitos humanos perante o Sistema Interamericano Proteção aos Direitos Humanos, ver Cardoso (2012).

14 A íntegra dos informes anuais da CIDH, em relação aos anos de 2010 a 2014, estão disponíveis na página eletrônica do órgão: http://www.oas.org/es/cidh/informes/anuales.asp. Acesso em 21 de jun. 2105.

${ }^{15}$ Peres (2014) indica que entre os anos de 2003 a 2013, 98,25\% dos casos analisados pela CIDH denunciavam o Estado brasileiro por violação às garantias judiciais e à proteção judicial.
} 
A despeito dessa importância crescente da atuação do SIDH para os movimentos sociais, organizações de Direitos Humanos e vítimas de violência, casos analisados pela CIDH e sentenciados pela Corte IDH permanecem sem soluções significativas junto ao Sistema de Justiça brasileiro, a exemplo do caso Sétimo Garibaldi.

\section{REFORMAS DO SISTEMA DE JUSTIÇA E GRAVES VIOLAÇÕES DE DIREITOS HUMANOS}

A reforma do Sistema de Justiça, especificamente a reforma do Poder Judiciário, entrou para a agenda política brasileira na década de 1990, articulada em um discurso de fortalecimento da democracia, que denunciava a hipertrofia da atividade judicial, em sobreposição às instâncias políticas representativas tradicionais. O protagonismo do Judiciário no processo de construção de decisões políticas dá seus primeiros sinais, após a Constituição Federal de 1988, com o ajuizamento de ações coletivas e individuais e ações diretas de inconstitucionalidades movidas em oposição a medidas econômicas, fiscais e previdenciárias adotadas pelo Poder Executivo: o questionamento do Plano Collor pelo desrespeito a direitos patrimoniais pela utilização de confiscos e desapropriação ${ }^{16}$, o programa de privatizações feito pelo governo de Fernando Henrique Cardoso, que teve diversas iniciativas questionadas pelo Judiciário, inclusive alteradas e atrasadas pelo Supremo Tribunal Federal (Marona, 2013). ${ }^{17}$

As propostas de reforma constitucional e infraconstitucional que

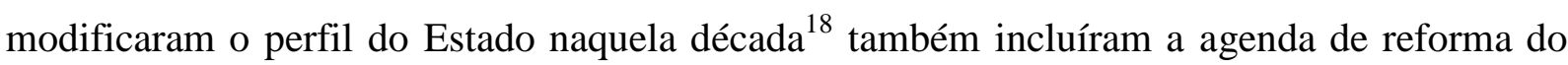
Judiciário em função dos aspectos materiais do seu funcionamento, mas principalmente em função do papel político que passou a exercer, em confrontar as decisões dos demais poderes - o fenômeno que se convencionou chamar de judicialização da política (Sadek, 2001). ${ }^{19}$ Os

\footnotetext{
${ }^{16}$ Arantes (1997) analisa o sistema híbrido do controle de constitucionalidade previsto na Constituição Federal de 1988, tomando como caso de estudo o plano econômico editado pelo governo Collor em 15 de março de 1990 e as decisões do Supremo Tribunal Federal em ações contrárias às medidas econômicas adotadas pelo governo.

${ }^{17}$ Viana et. al. (1997) aponta que a ambiguidade constitutiva da Carta de 1988, que adota o presidencialismo depois de ter incorporado muitas das instituições do regime parlamentarista, favoreceu a nova centralidade assumida pelo Poder Judiciário, levando-o a decidir impasses institucionais entre o Poder Executivo e o Legislativo. O redobrado intervencionismo do Estado sobre a vida econômica - como nos sucessivos planos de estabilização monetária - e as repercussões dramáticas que tiveram sobre os interesses privados, levou o Judiciário a se tornar o único lugar de defesa dos cidadãos e das empresas.

${ }^{18}$ Pereira (1998) analisa a reforma do Estado na década de 1990 em quatro aspectos básicos da sua reconstrução: a delimitação de sua abrangência institucional e os processos de redução do tamanho do Estado, a demarcação de seu papel regulador e os processos de desregulamentação, o aumento de sua capacidade de governança, e o aumento de sua governabilidade.

${ }^{19}$ Para análise do processo histórico de reforma do Judiciário no período indicado, ver Sadek (2004) que apresenta a posição dos integrantes do Sistema de Justiça, a partir de pesquisas realizadas entre 1993 a 2004, apontando, como resultado uma flexibilização do espírito corporativo dos membros do Judiciário, como por
} 
debates em torno das propostas de emenda constitucional que tramitaram no Congresso Nacional na década de 1990 (PEC n. 96/1992 e PEC n. 112/1995) e a aprovação das Leis n. 9.868 e 9.882 (que disciplinaram a ação direta de inconstitucionalidade, a ação declaratória de constitucionalidade e a arguição de descumprimento de preceito fundamental) abriram o direito processual constitucional a entidades representativas da sociedade para a emissão de pareceres, instituindo a figura do amicus curiae, com possibilidade de realização de audiências públicas, como recursos para ampliação da legitimidade democrática das decisões judiciais.

Em relação à credibilidade do órgão perante a sociedade, no mesmo período, o Congresso Nacional iniciou forte campanha para desacreditar as instituições judiciárias, com o apontamento de inúmeras irregularidades e processos de corrupção no interior dos tribunais, situação que culminou com a instauração da Comissão Parlamentar de Inquérito para apurar irregularidades praticadas por integrantes de tribunais superiores, de tribunais regionais, e de tribunais de justiça (Senado, 1999). O processo de desmoralização do Judiciário foi, inclusive, objeto de análise do Banco Mundial em trabalho que propôs um programa de reforma, com realce nos principais fatores que afetariam a qualidade do serviço prestado: longos processos judiciais ${ }^{20}$, excessivo acúmulo de processos, acesso limitado à população, falta de transparência e previsibilidade de decisões e frágil confiabilidade pública no sistema (Banco Mundial, 1996). ${ }^{21}$

Assim, a reforma do Judiciário iniciada na década de 1990, foi marcada por ações de contenção do movimento de hipertrofia do Judiciário que resultou em alterações do

exemplo, a aceitação de sua democratização e também um divisão entre a classe quanto ao controle externo a este poder e a sua composição e Sadek (2004a) que desenvolve os principais temas em debate à época, as mudanças em andamento e as perspectivas de reformas.

${ }^{20}$ Sobre o tema, Santos (2007) destaca a existência de dois tipos de morosidade: a sistemática e a ativa. A primeira decorre da burocracia, do positivismo e do legalismo e as medidas processuais adotadas em 2006 e 2007 (súmula impeditiva de recursos, prazo de 10 dias de pedidos de vista de processos nos tribunais, súmula vinculante, repercussão geral do recurso extraordinário) são importantes para enfrentar a morosidade sistêmica. A segunda decorre da interposição por parte de operadores do sistema judicial de obstáculos para impedir o desenvolvimento normal do processo para a solução do caso. "Os casos de morosidade activa são casos de processo 'na gaveta', de intencional não decisão em que, em decorrência de conflito de interesse em que estão envolvidos, é natural que as partes e os responsáveis por encaminhar uma decisão utilizem todos os tipos de escusas protelatórias possíveis (Santos, 2007, p.43). E aponta como exemplo a demarcação do território dos Pataxó Hã Hã Hãe que tramita há 25 anos nos tribunais brasileiros. Conclui observando que as medidas para enfrentarem a morosidade sistêmica podem garantir uma justiça mais célere, mas não necessariamente uma justiça mais cidadã.

${ }^{21}$ O projeto neoliberal implementado no Brasil na década de 1990 também pautou a reforma do Poder Judiciário. Daí, a influência das propostas do Banco Mundial contidas no Documento Técnico n. 319/1996 - "O Setor Judiciário na América Latina e no Caribe: elementos para reforma”, que propunha a adequação do Poder Judiciário à reforma econômica em curso nos países da América Latina, de modo a aumentar a eficiência e eficácia do sistema judicial, ou seja, diminuição da morosidade e aumento da previsibilidade, para a garantia das operações financeiras no país. 
desenho institucional que restringiram sua autonomia e possibilitaram maior controle sobre a jurisdição constitucional, criando freios institucionais. Também se relacionou à qualidade da prestação jurisdicional, influenciada pela expansão de programas neoliberais na economia e política brasileiras. As propostas de reforma, segundo Marona (2013), apontavam para dois aspectos - racionalização do sistema de controle de constitucionalidade e instituição de um controle externo ao Judiciário que fizesse frente a sua independência. $\mathrm{O}$ resultado dos debates sobre a reforma do Poder Judiciário culminou com a promulgação da Emenda Constitucional n. 45/2004, conhecida como a Emenda da Reforma do Judiciário que, conforme pontua Santos (2007), emerge de um conjunto de objetivos diversos, que vão desde a previsões que garantem maior acessibilidade ao Judiciário, passando pelo estabelecimento de uma justiça itinerante, até a adoção de medidas para garantir a celeridade e descongestionamento dos processos nos tribunais superiores, como a súmula vinculante e o efeito vinculante.

Em dezembro de 2004, ainda no bojo do processo de reforma do Judiciário, foi assinado pelos três Poderes o I Pacto de Estado em favor de um Judiciário mais rápido e republicano que apontou a morosidade dos processos judiciais e a baixa eficácia de suas decisões que "retardam o desenvolvimento nacional, desestimulam investimentos, propiciam a inadimplência, geram impunidade e solapam a crença dos cidadãos no regime democrático.” (Brasil, 2004). E apresentava dentre outros, o compromisso em criar um banco de dados com a identificação de denúncias contra o Brasil nos Sistemas Internacionais de Proteção aos Direitos Humanos e posterior estruturação, no âmbito do Poder Judiciário, de sistema de acompanhamento dos inquéritos e ações judiciais relacionados com os casos enfocados.

Especificamente para o campo da proteção dos Direitos Humanos, a Emenda Constitucional 45/2004 previu, nas hipóteses de grave violação de direitos humanos, que o Procurador-Geral da República poderá suscitar, perante o Superior Tribunal de Justiça (STJ), em qualquer fase do inquérito ou processo, incidente de deslocamento de competência (IDC) para a Justiça Federal, com a finalidade de assegurar o cumprimento de obrigações decorrentes de tratados internacionais de direitos humanos dos quais o Brasil seja parte.

Entretanto, passados onze anos da promulgação da emenda e da assinatura do I Pacto Republicano, foram suscitados apenas cinco incidentes de deslocamento ${ }^{22}$, sendo

\footnotetext{
${ }^{22}$ Foram os seguintes IDCs suscitados perante o STJ: IDC 01, referente ao assassinato da Missionária Dorothy Stang, cometidos por exploradores ilegais de madeira no interior do estado do Pará (indeferido, por não ficar demonstrado o descumprimento de obrigações decorrentes de tratados internacionais por inércia, negligência, falta de vontade política ou condições reais das instituições procederem a devida persecução penal); IDC 02, referente ao assassinato do advogado Manoel Bezerra de Mattos Neto, por grupos de extermínio que atuam nos estados da Paraíba e Pernambuco (deferido, porque constatada a incapacidade das instâncias e autoridades locais em oferecer respostas efetivas, reconhecida a limitação e precariedade dos meios por elas próprias); IDC 03,
} 
que não houve ainda julgamento definitivo, pela Justiça Federal, das ações judiciais relativas aos incidentes deferidos pelo STJ (os IDCs n. 02, 03 e 05). E sobre a criação de banco de dados com as denúncias contra o Estado brasileiro em sistemas internacionais de proteção aos direitos humanos para uma atuação do Judiciário sobre os casos, duas iniciativas foram realizadas - Observatório de Recomendações Internacionais sobre Direitos Humanos, pela então Secretaria de Direitos Humanos da Presidência da República ${ }^{23}$ e o programa Justiça Plena $^{24}$, pelo Conselho Nacional de Justiça. Entretanto, ambas iniciativas são incompletas, por não reunirem todas as denúncias feitas contra o Brasil, em especial aquelas feitas perante o SIDH: o observatório apresenta apenas os Relatórios da Organização das Nações Unidas, relativas ao mecanismo de Revisão Periódica Universal e o programa acompanhou, de acordo com o relatório de 2012 (CNJ, 2012) apenas oito casos em trâmite no SIDH. ${ }^{25}$

relativo a uma série de homicídios, desaparecimentos forçados e torturas cometidas por agentes policiais do estado de Goiás (deferido, porque constatada a ineficácia da atuação das autoridades locais, desnudando situação de grave omissão dos deveres do Estado); IDC 04, suscitado por Sandro Ricardo da Cunha Moraes, sobre sua aposentadoria por invalidez em decorrência de esquizofrenia paranoide e psicopatia (negado seguimento por não ter sido suscitado pelo Procurador-Geral da República, na forma do parágrafo 5, artigo 109, da Constituição Federal) e o IDC 05, relativo ao assassinato do promotor de justiça Thiago Farias Soares, relacionado a atuação de grupos de extermínio no estado de Pernambuco (deferido, porque constatada a dificuldade do estado de Pernambuco em reprimir e apurar crime praticado com grave violação de direitos humanos, em descumprimento a obrigações decorrentes de tratados internacionais de direitos humanos dos quais o Brasil é parte).

${ }^{23}$ O Observatório de Recomendações Internacionais sobre Direitos Humanos é uma plataforma de acesso público que reúne recomendações dirigidas ao Brasil por instâncias da Organização das Nações Unidas (ONU) e da Organização dos Estados Americanos (OEA) que também apresenta informações sobre a situação de cumprimento dessas recomendações. Ver página eletrônica do observatório: http://www.observadh.sdh.gov.br/portal. Acesso em 15 de jun.2015.

${ }^{24}$ O Programa Justiça Plena, lançado em 2010, pelo CNJ, monitora e dá transparência ao andamento de processos considerados de grande repercussão social, relacionadas a questões criminais, ações civis públicas, ações populares, processos em defesa do direito do consumidor e ambientais. Participam da iniciativa, além do CNJ, o Ministério da Justiça, a Advocacia- Geral da União, a então Secretaria de Direitos Humanos da Presidência da República, o Conselho Nacional do Ministério Público, a Ordem dos Advogados do Brasil, a Defensoria Pública da União e dos Estados e a Procuradoria Federal dos Direitos do Cidadão. O acesso pleno aos processos acontece por meio do Sistema de Acompanhamento de Processos de Relevância Social (SAPRS) e é concedido apenas aos representantes cadastrados, que podem consultar e atualizar o banco de dados. A Corregedoria Nacional de Justiça do CNJ faz a inclusão dos processos que são de interesse público e têm potencial para repercutir na sociedade.

${ }^{25}$ De acordo com o relatório do Programa Justiça Plena (CNJ, 2012) foram os seguintes casos contra o Estado brasileiro em trâmite no SIDH, acompanhados pelo órgão até 2012: Damião Ximenes Lopes, Sétimo Garibaldi, José Dutra da Costa, Sebastião Camargo Filho, comunidades indígenas da Terra Indígena Raposa Serra do Sol, situação dos internos do presídio Urso Branco, Massacre de Carandiru, Escher e outros, situação dos internos da Unidade de Internação Socioeducativa (UNIS) de Cariacica. Observe-se que o relatório datado de 2012 é o mais recente lançado pelo CNJ sobre o programa. 


\section{O CASO SÉTIMO GARIBALDI E AS CONTRADIÇÕES DO SISTEMA DE JUSTIÇA FRENTE A DECISÕES DO SIDH}

\subsection{Contexto da violência no campo no estado do Paraná na década de 1990.}

Os conflitos socioterritoriais, como afirmam Marés e Sauer (2013), fazem parte da realidade brasileira: a concentração fundiária, o avanço do modelo do agronegócio, mobilizações populares de luta por direitos e inexistências de políticas públicas estruturantes de acesso à terra são elementos que reiteram no tempo e no espaço os conflitos, sendo previsível a ocorrência de novas situações. Para Medeiros (2014) as disputas em torno da terra revestiramse de diversas formas ao longo do tempo, mas sua raiz está no processo de transformação da terra em equivalente de mercadoria e, portanto, na criação de condições para sua livre compra e venda no mercado e apropriação da renda fundiária.

Os dados sobre conflitos fundiários e violência no campo no Brasil referentes ao ano de no ano de 2014 indicam a permanência de um padrão de conflitualidade que constitui a história brasileira e cujo cerne é o acesso à terra. A publicação Conflitos no Campo (Canuto et al., 2014) aponta a ocorrência de trinta e seis assassinatos e cinquenta e seis tentativas de assassinatos e concentraram-se nos estados do Pará, Maranhão, Mato Grosso e Rondônia, no ano de 2013. As ocorrências de pistolagem (17.695 situações) aparecem em todo o Brasil, mas também estão concentradas: $49 \%$ na região Norte, com destaque para o Pará e 27,50\%, no Nordeste, com primazia do Maranhão. Essas duas regiões, somadas, são responsáveis por $76 \%$ dos casos.

Observe-se que dos cento e vinte e cinco casos em diferentes fases contra o Estado brasileiro em trâmite na $\mathrm{CIDH}$, cerca de cinquenta casos referem-se à violência no campo, considerando tanto comunidades campesinas como indígenas e quilombolas. ${ }^{26} \mathrm{E}$ mais, das quatro condenações do Estado brasileiro pela Corte IDH, duas referem-se à violência no campo, ambas sobre violações à Convenção Americana relacionadas a crimes que ocorreram no Estado do Paraná. ${ }^{27}$ Especificamente esse Estado, entre os anos 1990 e início nos anos 2000, apresentava maior incidência de violações de Direitos Humanos contra trabalhadores rurais. A Comissão Pastoral da Terra (CPT, et al, 2003) aponta que a situação agravou-se principalmente durante os anos de 1995 a 2002, quando foi estabelecida uma política repressiva contra os trabalhadores pelo governo estadual. A Secretaria de Segurança do estado iniciou uma série de despejos em acampamentos de famílias sem terra naquele período:

\footnotetext{
26 Informações obtidas na página eletrônica da Comissão Interamericana de Direitos Humanos: http://www.oas.org/es/cidh/. Acessado em 15 de jun. 2015. ${ }^{27}$ Informações obtidas na página eletrônica da Corte Interamericana de Direitos Humanos: http://www.corteidh.or.cr/index.php/es. Acessado em 15 de jun. 2015.
} 
fazendeiros intimidavam os trabalhadores rurais, empregando grupos armados e pressionavam o governo do Paraná que fizesse despejos de famílias sem terra; em diversas operações de despejo violentas, foram identificados, atuando em conluio com a força pública, pistoleiros particulares, contratados pelos proprietários das terras objeto do despejo. Segundo diversas fontes, muitos destes casos não foram investigados nem julgados (CPT, et al, 2003).

\subsection{O assassinato do trabalhador rural Sétimo Garibaldi e os desdobramentos do caso no SIDH}

Em novembro de 1998, a Fazenda São Francisco, de propriedade de Maurílio Favoretto, Darci Favoretto, Morival Favoretto e Wilson Ferreira, localizada no Município de Querência do Norte, Estado do Paraná foi ocupada por cerca de setenta famílias de trabalhadores rurais integrantes do Movimento dos Trabalhadores Rurais Sem Terra (MST). Em 27 de novembro, de madrugada, ocorreu uma operação violenta de despejo, realizada por um grupo armado civil, composto de aproximadamente vinte homens, encapuzados e contratados pelos fazendeiros. Sétimo Garibaldi, que ocupava a fazenda com os demais trabalhadores, foi atingido por um projétil calibre 12, que o atingiu na coxa esquerda, causando hemorragia que o levou à morte. O homicídio foi denunciado à Polícia Militar do Estado do Paraná ainda em 27 de novembro e partir de então, foi iniciado o inquérito policial n. ${ }^{\circ}$ 179/98 (CIDH, 2007b).

Várias das testemunhas oculares presentes no despejo forçado, por fazerem parte do assentamento, identificaram Morival Favoretto, co-proprietário da Fazenda São Francisco, constituindo o grupo armado que tentou efetuar o despejo. A polícia compareceu à Fazenda São Francisco na data do fato, sem sequer levar o cadáver de Sétimo Garibaldi. O inquérito policial n. 179/98 da Delegacia de Polícia de Loanda foi arquivado sem indicar responsáveis pelo crime. Apesar dos indícios e das inúmeras testemunhas que garantiram que a autoria do fazendeiro Morival Favoreto, como mandante não houve denúncias. (CIDH, 2007b).

Diante de tais omissões, as organizações não-governamentais Terra de Direitos e Justiça Global, a Comissão Pastoral da Terra, o MST e a Rede Nacional de Advogados Populares (RENAP) denunciaram o caso em maio de 2003 à Comissão Interamericana de Direitos Humanos. O caso foi registrado na CIDH sob o número 12.478 e após trâmite regular, no $127^{\circ}$ Período Ordinário de Sessões, em 27 de março de 2007, a 
Comissão aprovou o Relatório de Admissibilidade e Mérito n. 13/07, que faz as seguintes recomendações ao Estado do Brasil:

1. Realizar uma investigação completa, imparcial e eficaz da situação, com o objetivo de estabelecer a responsabilidade a respeito aos fatos relacionados com o assassinato de Sétimo Garibaldi, punir os responsáveis e determinar os obstáculos que impediram que fossem realizados tanto uma investigação como um julgamento efetivos.

2. Reparar plenamente os familiares de Sétimo Garibaldi, incluindo o aspecto tanto moral como material, pelas violações de direitos humanos determinadas no [...] relatório $[\ldots]$.

3. Adotar e implementar as medidas necessárias para uma eficaz implementação da disposição constante do artigo 10 do Código Processual Penal Brasileiro no que diz respeito a toda investigação policial, bem como para o julgamento dos fatos puníveis ocorridos em relação a despejos forçados em assentamentos de trabalhadores sem terra, com consequiências de morte, de maneira a ajustar-se aos parâmetros impostos pelo Sistema Interamericano.

4. Adotar e implementar as medidas necessárias para que sejam observados os direitos humanos nas políticas governamentais que tratam da ocupação de terras, levando em consideração a obrigação imposta pelo artigo 28 , em relação com o artigo 1.1 da Convenção Americana, segundo determina a Cláusula Federal.

5. Adotar e implementar medidas adequadas dirigidas aos funcionários de justiça e da polícia, a fim de evitar a proliferação de grupos armados que façam despejos arbitrários e violentos. (CIDH, 2007a)

A $\mathrm{CIDH}$ concedeu prazo de dois meses ao Brasil para informar a implementação das recomendações. Ainda em 2007, a Comissão convidou o Estado e peticionários para a uma reunião de trabalho sobre a implementação das recomendações neste caso, celebrada no $130^{\circ}$ Período Ordinário de Sessões, em 11 de outubro de 2007. Nessa reunião, ambas as partes apresentaram informações e a CIDH enfatizou a importância do cumprimento das recomendações formuladas no relatório de mérito. No entanto, os prazos para que o Estado apresentasse informações sobre o cumprimento das recomendações transcorreram sem que a Comissão recebesse qualquer informação.

Assim, ante a falta de implementação satisfatória das recomendações constantes do Relatório de Mérito n. 13/07, a CIDH decidiu submeter o caso à jurisdição da Corte IDH em 21 de dezembro de 2007, alegando a responsabilidade do Estado brasileiro decorrente do descumprimento da obrigação de investigar e punir os responsáveis pelo homicídio do Sétimo Garibaldi, solicitando a declaração pela Corte da responsabilidade do Brasil pela violação dos artigos 8 (Garantias Judiciais) e 25 (Proteção Judicial) da CADH, com relação à obrigação geral de respeito e garantia dos direitos humanos e ao dever de adotar medidas legislativas e de outro caráter no âmbito interno, previstos, respectivamente, nos artigos 1.1 e 2 do referido tratado, também em consideração às diretrizes emergentes da cláusula federal contida no artigo 28 do mesmo instrumento, em prejuízo de Iracema Cioato 
Garibaldi, viúva de Sétimo Garibaldi, e seus seis filhos. A Comissão solicitou à Corte que ordenasse ao Estado também a adoção de medidas de reparação. (CIDH, 2007b)

Em 23 de setembro de 2009, quase dois anos após a submissão do caso, a Corte IDH proferiu sentença, declarando que o Estado brasileiro violou os direitos às garantias judiciais e à proteção judicial reconhecidos nos artigos 8.1 e 25.1 da Convenção Americana, em relação com o artigo 1.1 da mesma, em prejuízo dos familiares de Sétimo Garibaldi e determinou que cabe ao Brasil conduzir eficazmente e dentro de um prazo razoável o Inquérito e qualquer processo que chegar a abrir, como consequência deste, para identificar, julgar e, eventualmente, sancionar os autores da morte do senhor Garibaldi. Da mesma maneira, o Estado deve investigar e, se for o caso, sancionar as eventuais faltas funcionais nas quais poderiam ter incorrido os funcionários públicos a cargo do Inquérito (Corte IDH, 2009).

Para concluir sobre a condenação do Estado brasileiro, a Corte analisou os procedimentos que vinculam ou constituem o pressuposto de um processo judicial, particularmente, as tarefas de investigação de cujo resultado depende o início e o avanço do mesmo. Examinou as alegações da CIDH e peticionários sobre o inquérito policial n. ${ }^{\circ}$ 179/98, particularmente com relação aos atos e omissões ocorridos depois de 10 de dezembro de 1998 (data da ratificação da jurisdição da Corte pelo Brasil), para determinar se existiram violações aos direitos às garantias e à proteção judiciais nesse procedimento interno. $O$ tribunal verificou a ocorrência de falhas e omissões no inquérito policial quanto à falta de recebimento de testemunhos "prima facie" indispensáveis, falta de esclarecimento sobre contradições entre testemunhos, inutilizações e omissões com relação à prova, provas perdida, falta de cumprimento de diligências ordenadas, erro na petição de arquivamento do inquérito e a demora no desenvolvimento do inquérito. Em consequência, a Corte concluiu que as autoridades estatais não atuaram com a devida diligência no inquérito da morte de Sétimo Garibaldi, o qual, ademais, excedeu um prazo razoável (Corte IDH, 2009).

\subsection{Atuação do Sistema de Justiça a partir da condenação da Corte IDH - contradições no caso concreto}

A partir da sentença da Corte IDH no caso Sétimo Garibaldi versus Brasil, o Sistema de Justiça brasileiro tem atuado de forma contraditória (postura que não diverge de outros casos, conforme já demonstrado) acerca do andamento da ação penal que apura os responsáveis pelo homicídio do trabalhador rural. A condenação do Estado brasileiro pela 
Corte impulsionou lentamente o trâmite do inquérito policial n. ${ }^{\circ}$ 179/98: entre 2009 e 2010, foram tomadas declarações de quatro testemunhas e um suposto responsável pelo assassinato e o Ministério Público do estado do Paraná emitiu Relatório Circunstanciado das Investigações, em 10 de maio de 2010. Já em abril de 2011, os autos do inquérito foram remetidos ao Poder Judiciário para apreciação do Ministério Público e do juízo competente. E finalmente, em 30 de junho de 2011, o Ministério Público ofereceu denúncia contra Morival Favoreto. A Procuradoria Geral do Estado de Paraná requereu o trâmite com urgência do caso e a realização de algumas diligências por parte da Polícia Civil. A audiência de instrução e julgamento foi realizada em 22 de novembro de 2011.

Entretanto, Morival Favoreto impetrou habeas corpus junto ao Tribunal de Justiça do Paraná, com o objetivo de trancar a ação penal, o qual foi concedido, em 01 de dezembro de 2011. O acórdão não faz qualquer menção à sentença da Corte Interamericana de Direitos Humanos, ${ }^{28}$ que motivou o desarquivamento do inquérito policial e a denúncia oferecida pelo Ministério Público:

\begin{abstract}
'HABEAS CORPUS'. HOMICIDIO QUALIFICADO. ART. 121, § 2, IV DO CP. DESARQUIVAMENTO DO INQUÉRITO POLICIAL E OFERECIMENTO DE DENÚNCIA. PEDIDO DE TRANCAMENTO DA AÇÃO PENAL. ACOLHIMENTO. AUSÊNCIA DE PROVAS FORMAL E SUBSTANCIALMENTE NOVAS. CONSTRANGIMENTO ILEGAL EVIDENCIADO. ORDEM CONCEDIDA. - A pretensão de trancamento da ação penal exige que se verifique se houve alteração do panorama probatório dentro do qual fora concebido e acolhido o pedido de arquivamento do inquérito policial (STJ, RHC 18561, DJ de 01/08/2006), a autorizar o oferecimento da denúncia criminal contra o ora paciente, ou seja, se foi produzida prova formal e substancialmente nova, amparada Habeas Corpus Crime $\mathrm{n}^{\circ}$ 825907-6. em fatos anteriormente desconhecidos, que tenha idoneidade para alterar o juízo precedente proferido sobre a desnecessidade da persecução penal (cfme. Tourinho Filho, Código de Processo Penal Comentado, vol. 1, $4^{\text {a }}$ Ed., Saraiva, 1999, p. 89/90). - Para tal finalidade, é necessário verificar se as "novas provas" constituem base empírica apta para alterar o conjunto probatório existente por ocasião do pedido de arquivamento de modo a suportar, com justa causa, o oferecimento de denúncia, pois, como tem decidido o colendo Supremo Tribunal Federal, "As "novas provas" serão aquelas capazes de autorização do início da ação penal, com alteração do conjunto acolhido no arquivamento (RTJ 91/831; 32/35; 63/620;40/111; 47/53; 188/200; 185/970; 186/624)" (Roberto Rosas, Direito Sumular, $13^{a}$ edição, Editora Malheiros, 2006, pág. 267). - Desse modo, em que pese tenham alguns dos assentados reconhecido o paciente dentre as pessoas que invadiram o acampamento do MST no dia dos fatos (cfme. declarações contidas no inquérito antes do arquivamento), tendo o Dr. Promotor de Justiça apresentado argumentos que, a par destes reconhecimentos, conduziram à conclusão de que não se produziram elementos para esclarecer a Habeas Corpus Crime $\mathrm{n}^{\circ}$ 825907-6. autoria delitiva e tendo requerido o arquivamento do respectivo Inquérito Policial, o que foi acolhido pela $\mathrm{MM}^{\mathrm{a}}$ Juíza de Direito, a posterior instauração de persecução penal contra o indiciado só poderia
\end{abstract}

${ }^{28}$ O desembargador Naor R. de Macedo Neto apresentou voto divergente, negando o habeas corpus ao fazendeiro, no qual apenas cita, a título de relatório e não como fundamento da decisão, a sentença da Corte IDH. 
ocorrer se tivessem surgido "novas provas" capazes de modificar o panorama probatório anterior, o que não ocorreu, como se demonstrou pela análise dos novos elementos colhidos após o desarquivamento. - Não havendo, no caso, a produção de "novas provas" que modificassem a matéria de fato e autorizassem o oferecimento de denúncia em desfavor do paciente, é de rigor que se reconheça estar sofrendo constrangimento ilegal. - $\mathrm{O}$ oferecimento de denúncia, com fundamento em base empírica existente em inquérito policial arquivado, a pedido do Ministério Público, constitui constrangimento ilegal e viola o princípio constitucional da segurança jurídica, pois, se assim não for, o investigado a qualquer momento, antes de consumado o prazo prescricional, poderá ser submetido a processo penal, independentemente de novas provas, o que é inadmissível, nos termos do art. 18 do Código de Processo Penal e do enunciado da Súmula 524 do egrégio Supremo Tribunal Federal. Habeas Corpus Crime n ${ }^{\circ} 825907-6$. VISTO, relatados e discutidos estes autos de HABEAS CORPUS N ${ }^{\circ}$ 825907-6, da Comarca de Loanda, Vara Criminal e Anexos, em que é impetrante DOUGLAS BONALDI MARANHÃO (advogado) e paciente MORIVAL FAVORETO.

O trâmite da ação penal até este ponto demonstra as contradições do Sistema de Justiça no âmbito estadual: se por um lado o Ministério Público do Paraná fundamenta a propositura da ação penal no desarquivamento do inquérito policial em função da decisão da Corte Interamericana de Direitos Humanos, por outro lado o Tribunal de Justiça do Paraná sequer menciona esta sentença em seu acórdão de concessão de habeas corpus para o trancamento da ação penal.

Contra esta decisão, o Ministério Público do Paraná interpôs Recurso Especial n. ${ }^{\circ}$ 1.351.177-PR em junho de 2012 junto ao STJ, conforme estabelece o artigo 105, III, da Constituição Federal, com fundamento na violação da legislação federal (dispositivos do Código de Processo Penal), mas também em violação do artigo $68, \S 1^{\circ}$ combinado com o artigo 28, $\S 2^{\circ}$ da Convenção Americana de Direitos Humanos. ${ }^{29}$ O Recurso Especial sustenta que, a partir do momento em que o estado do Paraná, pelas diversas esferas de poder implicadas (Executivo, Judiciário e Ministério Público) tomou conhecimento da decisão da Corte IDH, cada instituição integrante do sistema de justiça criminal tornou-se obrigada a cumprir, nas respectivas esferas de especialização, a sentença. $\mathrm{O}$ acórdão do Tribunal de Justiça do Paraná teria contrariado a Convenção Americana porque, embora ciente da sentença da Corte IDH, ancorou-se tão somente na interpretação e aplicação de dispositivo do Código de Processo Penal:

A um só tempo, o TJPR nem se esforçou para cumprir parte que lhe cabia na execução da sentença da Corte Interamericana, nem se esforçou para

\footnotetext{
$\overline{29}$ Convenção Americana de Direitos Humanos. Artigo 28. 2. No tocante às disposições relativas às matérias que correspondem à competência das entidades componentes da federação, o governo nacional deve tomar imediatamente as medidas pertinente, em conformidade com sua constituição e suas leis, a fim de que as autoridades competentes das referidas entidades possam adotar as disposições cabíveis para o cumprimento desta Convenção. Artigo 68. 1. Os Estados Partes na Convenção comprometem-se a cumprir a decisão da Corte em todo caso em que forem partes.
} 
harmonizar a aplicação e a interpretação do direito interno (artigo 18 do CPP e súmula 524 do STF) com o inteiro teor da sentença da Corte Interamericana. (Brasil, 2012).

A $6^{a}$ Turma do STJ iniciou o julgamento do recurso três anos após sua interposição, em 13 de outubro de 2015, finalizando-o somente em 17 de março de 2016. A decisão final da turma foi pelo não conhecimento do Recurso Especial, entretanto três posições foram firmadas: i) pelo não conhecimento do recurso, tese vencedora; ii) pelo conhecimento parcial do recurso, negando-lhe provimento; iii) pelo conhecimento e provimento do recurso. Até a finalização do presente artigo, o STJ ainda não havia publicado o acórdão e os votos à exceção do voto do ministro Rogério Schietti Cruz, que apresentou voto-vista pelo conhecimento e provimento do recurso.

Como não há notícia até a finalização do presente artigo sobre interposição de Recurso Extraordinário ao STF, está mantida a decisão do Tribunal de Justiça do Paraná que decidiu pelo trancamento da ação penal, ao conceder o habeas corpus a Morival Favoreto.

\section{CONCLUSÕES PRELIMINARES}

A sentença sobre o caso Sétimo Garibaldi permanece sem cumprimento quanto à determinação da Corte IDH ao Estado brasileiro de condução eficaz e dentro de um prazo razoável o inquérito policial e qualquer processo que chegar a abrir, como consequência deste, para identificar, julgar e, eventualmente, sancionar os autores da morte do senhor Garibaldi (Corte IDH, 2009). O trancamento da ação penal pelo habeas corpus concedido ao fazendeiro pelo Tribunal de Justiça impede a condução de investigação e ação penal para a responsabilização dos autores do assassinato.

Tratando-se de pesquisa ainda em curso, as conclusões do artigo são preliminares e indicam que o tratamento dado pelo Sistema de Justiça ao caso Sétimo Garibaldi demonstra contradições de seus órgãos, também vistas no tratamento de outros casos do SIDH em relação ao Estado Brasileiro: se por um lado houve uma atuação diligente do Ministério Público em desarquivar o inquérito policial e denunciar o mandante do crime com base na sentença da Corte IDH, além de interpor Recurso Especial alegando violação expressa da Convenção Americana de Humanos, o Tribunal de Justiça do estado do Paraná não cita a decisão da Corte em seu acórdão de trancamento da ação penal e o Superior Tribunal de Justiça sequer conheceu do Recurso Especial, a despeito de um único integrante da turma de julgamento ter conhecido e dado provimento ao mesmo. 
As reformas feitas no Sistema de Justiça, que culminaram com a promulgação da Emenda Constitucional 45/2004 e a assinatura do I Pacto de Estado em favor de um Judiciário mais rápido e republicano (e os pactos sucessivos), não foram capazes de estabelecer mecanismos e instrumentos que permitissem o cumprimento das recomendações e sentenças da $\mathrm{CIDH}$ e Corte IDH, órgãos que o Estado brasileiro reconheceu como competentes para decidirem sobre violações de Direitos Humanos ocorridas no país. As poucas iniciativas criadas como o Observatório de Recomendações Internacionais sobre Direitos Humanos e o programa Justiça Plena não trouxeram ganhos ao trâmite da ação penal relativa ao assassinato de Sétimo Garibaldi, mesmo diante da sentença da Corte.

A reflexão que se segue, portanto, é como tais decisões podem ser cumpridas pelo Sistema de Justiça. Cabe verificar (sendo este o próximo passo da pesquisa em questão) se a partir da inter-relação entre Ministério Público, Poder Judiciário, Poder Executivo, vítimas e organizações de Direitos Humanos e movimentos sociais é possível levantar práticas e experiências que contribuam com a reforma do Sistema de Justiça para garantir o tratamento das graves violações de Direitos Humanos já reconhecidas pelo Sistema Interamericano.

\section{REFERÊNCIAS}

ABRAMOVICH, Vítor. Das violações em massa aos padrões estruturais: novos enfoques e clássicas tensões no Sistema Interamericano de Direitos Humanos. Revista Sur, São Paulo v. 6, n. 11, p. 7-39, dez. 2009.

ARANTES, Rogério Bastos. Judiciário e política no Brasil. São Paulo: Idesp, 1997.

BANCO MUNDIAL. Documento Técnico n. 319/96 - O setor judiciário na América Latina e no Caribe: elementos para a reforma. Washington: BIRD, 61 p. 1996.

BRASIL. Pacto de Estado em favor de um Judiciário mais Rápido e Republicano. Exposição de motivos n. 204, de 15 de dezembro de 2004.

BRASIL. Tribunal de Justiça do Paraná. Habeas Corpus n. ${ }^{\circ}$ 825907-6. Curitiba, PR, 01 dez. 2011.

BRASIL. Superior Tribunal de Justiça. Recurso Especial n. ${ }^{\circ}$ 1.351.177-PR. Rel. Min. Ericson Maranhão. Brasília, DF,17 mar.2016.

BERNARDES, Márcia Nina. Aspectos Transnacionais da Luta Contra a Violência Doméstica e Familiar no Brasil. Direito, Estado e Sociedade, Rio de Janeiro, n.45, p. 119 a 144, jul/dez 2014. 
CANUTO, Antônio; SILVA LUZ, Cássia Regina; COSTA, Edmundo Rodrigues. (coords.) Conflitos no campo Brasil 2014. Comissão Pastoral da Terra. Goiânia: CPT Nacional, 2014.

CARDOSO, Evorah Lusci Costa. Litígio estratégico e Sistema Interamericano de Direitos Humanos. Belo Horizonte: Fórum, 2012.

CIDH. Relatório n. ${ }^{\circ}$ 54/01. Caso 12.051. Maria da Penha Maia Fernandes, de 4 de abril de 2001.

CIDH. Relatório de Admissibilidade e Mérito n. ${ }^{\circ}$ 13/07. Caso 12.478. Sétimo Garibaldi, de 27 de março de 2007(a).

CIDH. Demanda perante a Corte Interamericana de Direitos Humanos no caso Sétimo Garibaldi (Caso 12.478) contra a República Federativa do Brasil, de 24 de dezembro de 2007(b).

CNJ. Programa Justiça Plena. 2012.

CORTE IDH. Caso Sétimo Garibaldi versus Brasil. Sentença de 23 de setembro de 2009. Serie C No. 203.

CORTE IDH. Caso Gomes Lund y otros ("Guerrilha do Araguaia") versus Brasil. Sentença de 24 de novembro de 2010. Serie C No. 219.

CORTE IDH. Caso Gomes Lund y otros ("Guerrilha do Araguaia") versus Brasil. Supervisão de Cumprimento da Sentença. Resolução da Corte Interamericana de Direitos Humanos de 17 de outubro de 2014.

COMISSÃO PASTORAL DA TERRA, et al. Crimes do Latifúndio. In: REDE DE JUSTIÇA SOCIAL E DIREITOS HUMANOS. Direitos Humanos no Brasil 2003. São Paulo, 2003.

GARCIA, Luciana Silva. Nada é impossível de mudar: julgamento de violações de direitos humanos ocorridas na ditadura militar brasileira. In: ASSY, Bethania et al. Direitos Humanos: Justiça, verdade e memória. Rio de Janeiro: Lumen Juris, 2012.

MACDOWELL, Cecília. Ativismo jurídico transnacional e o Estado: reflexões sobre os casos apresentados contra o Brasil na Comissão Interamericana de Direitos Humanos. Revista Sur, São Paulo n. 7, ano 4, p. 26-57, 2007.

. Da delegacia da mulher à Lei Maria da Penha: Absorção/tradução de demandas feministas pelo Estado. Revista Crítica de Ciências Sociais, Coimbra, n. 89, p. 153-170, jun. 2010 .

MARÉS, Carlos Frederico; SAUER, Sérgio (coord.). Casos emblemáticos e experiências de mediação: análise para uma cultura institucional de soluções alternativas de conflitos fundiários rurais. Brasília: Ministério da Justiça, Secretaria de Reforma do Judiciário, 2013.

MARONA, Marjorie Corrêa. Reforma do Judiciário no Brasil. In: Avritzer, Leonardo et al. Dimensões políticas da justiça. Rio de Janeiro: Civilização brasileira, 2013. 
MEDEIROS, Leonilde Servolo de. Conflitos fundiários e violência no campo. In: CANUTO, Antônio; SILVA LUZ, Cássia Regina; COSTA, Edmundo Rodrigues. (coords.) Conflitos no campo Brasil 2014. Comissão Pastoral da Terra. Goiânia: CPT Nacional, 2014, pp. 26-31.

PEREIRA, Luiz Carlos Bresser. A reforma do Estado dos anos 90: lógica e mecanismos de controle. Revista Lua Nova, São Paulo, n. 45, p. 49-95, 1998.

PERES, Luciana. O Brasil no Sistema Interamericano de Proteção aos Direitos Humanos: estudo do acesso à justiça como tema recorrente de violação de Direitos Humanos [trabalho de conclusão de curso].Brasília: Escola Nacional de Administração Pública - ENAP, Curso de Especialização em Políticas Públicas de Direitos Humanos; 2014.

SADEK, Maria Tereza (org.). Reforma do Judiciário. São Paulo: Fundação Konrad Adenauer, 2001.

SADEK, Maria Tereza; FAISTING, André Luiz, et al. O Sistema de Justiça. Rio de Janeiro: Centro Edelstein de Pesquisas Sociais, 2010.

- SADEK, Maria Tereza. Poder Judiciário: perspectivas de reforma. Opinião Pública, Campinas, vol. 10, n, 1, maio, p. 01-62, 2004.

Judiciário: mudanças e reformas. Estudos avançados. São Paulo, n. 18, p. 79101, 2004(a). Disponível em: http://www.scielo.br/pdf/ea/v18n51/a05v1851.pdf.

SANTOS, Boaventura de Sousa. Os conflitos urbanos no Recife: o caso do Skylab. Revista Crítica de Ciências Sociais, Coimbra, n. 08, pp. 09-60,1983.

. Para uma revolução democrática da justiça. São Paulo: Cortez, 2007.

SENADO. Relatório final da Comissão Parlamentar de Inquérito, criada pelo requerimento n. 118, de 1999.

VENTURA, Deisy; CETRA, Raíza Ortiz. O Brasil e o Sistema Interamericano de Direitos Humanos: de Maria da Pena à Belo Monte. In: SILVA FILHO, José Carlos Moreira; TORELLY, Marcelo (org.). Justiça de Transição nas Américas: olhares interdisciplinares, fundamentos e padrões de efetivação. Belo Horizonte: Fórum, 2013.

VIANNA, Luiz Wernneck et al. Corpo e Alma da magistratura brasileira. Rio de Janeiro: Revan, 1997. 